\title{
Self-Organized Cultural Cycles and the Uncertainty of Archaeological Thought
}

\author{
Aleksandr Diachenko ${ }^{1}$ (D) . Iwona Sobkowiak-Tabaka²
}

Accepted: 4 January 2022 / Published online: 12 January 2022

(c) The Author(s) 2022

\begin{abstract}
Contributing to the issue of complex relationship between social and cultural evolution, this paper aims to analyze repetitive patterns, or cycles, in the development of material culture. Our analysis focuses on culture change associated with sociopolitical and economic stasis. The proposed toy model describes the cyclical character of the quantitative and qualitative composition of archaeological assemblages, which include hierarchically organized cultural traits. Cycles sequentially process the stages of unification, diversity, and return to unification. This complex dynamic behavior is caused by the ratio between cultural traits' replication rate and the proportion of traits of the higher taxonomic order's related unit. Our approach identifies a shift from conformist to anti-conformist transmission, corresponding with open and closed phases in cultural evolution in respect to the introduction of innovations. The model also describes the dependence of a probability for horizontal transmission upon orders of taxonomic hierarchy during open phases. The obtained results are indicative for gradual cultural evolution at the low orders of taxonomic hierarchy and punctuated evolution at its high orders. The similarity of the model outcomes to the patters of material culture change reflecting societal transformations enables discussions around the uncertainty of explanation in archaeology and anthropology.
\end{abstract}

Keywords Cultural evolution · Diversity · Taxonomic hierarchy · Innovation · Replacement

Aleksandr Diachenko

adiachenko@iananu.org.ua

1 Institute of Archaeology, National Academy of Sciences of Ukraine, Kyiv, Ukraine

2 Faculty of Archaeology, Adam Mickiewicz University in Poznań, Poznań, Poland 


\section{Introduction}

Discussions on the evolutionary development of cultural traits as the result of either adaption to the environment and socioeconomic transformations or migrationist approaches to culture change have generally framed the clash of archaeological paradigms for over a century. This debate returned to the key topics of world archaeology during the ongoing Third Science Revolution in archaeology, as defined by K. Kristiansen (2014). The aDNA and strontium isotope data significantly bias current understandings of culture change towards migrationist explanations (e.g., Furholt, 2021). At the same time, fine-grained chronologies based on the large series of AMS dates provide a strong ground for testing the evolutionary models. Studies over the last two decades empirically identified repetitive patterns, or cycles, in social and cultural evolution. Such patterns extend the migrationist-evolutionary debate to the factors and mechanics of long-term human development considered by Darwinian archaeology and the archaeology of complex systems (e.g., Bentley \& Maschner, 2004, 2009; Boyd \& Richerson, 1985, 2005; Cavalli-Sforza \& Feldman, 1981; Lyman \& O’Brien, 1998; Mesoudi, 2011; O’Brien \& Lyman, 2000; O'Brien \& Shennan, 2010; Shennan, 2002, 2008; Shennan, 2009).

Contributing to our understanding of the complex relationship between social and cultural evolution, this paper aims to analyze the internal factors which cause the cyclical behavior of hierarchically organized material culture. Similar to evolutionary biology and paleontology, archaeology traditionally addresses its data through taxonomic ordering. Numerous discussions on the classification of material culture demonstrate the lack of agreement on strict rules producing taxonomic units as measures of similarities in material culture. However, these units' hierarchical organization provides a credible understanding of data structure (O'Brien \& Lyman, 2000; Lyman \& O’Brien, 2003; cf. Premo, 2021). This paper aims to understand how the behavior of cultural traits at different taxonomic orders is interrelated. We use the term "orders" in respect to levels of taxonomic hierarchy, sequentially numbered from the bottom to top.

Cyclical patterns in the dynamics of different phenomena have been considered since the philosophers of Ancient Greece (e.g., Diachenko et al., 2020; Gronenborn et al., 2014). This study considers repetitive patterns (cycles) as representing the transition of archaeological assemblages from more unified to more diverse and then back to more unified. We distinguish between two types of such cultural cycles, which may be exemplified by the following empirical cases. The recent studies of D. Gronenborn and his co-authors identified cycles in the unification and diversity of LBK pottery styles, which correlate with cycles of social dynamics and conflict among the LBK populations of Central Europe (Gronenborn et al., 2014, 2017, 2018, 2020; see also Mosionzhnik, 2006; Turchin, 2003; Turchin \& Nefedov, 2009). In contrast with D. Gronenborn and his co-authors' results, the work on the Western Tripolye culture in Eastern Europe indicated a similar cyclical pattern of unification and diversity of pottery forms, which does not correspond with the transformations in socioeconomic organization or spatial demography of this population (Diachenko et al., 2020). 
These two types of cultural cycles are conditionally labeled as "reflective cycles" and "self-organized cycles." Reflective cycles (exemplified by the LBK case) characterize the socioeconomic and spatio-demographic transformations mirrored in material culture. Self-organized cycles (exemplified by the Western Tripolye culture case), which referred to social stasis, are assumed to result from the neutral (unbiased) cultural evolution or conformist (biased) transmission. The latter is associated with the disproportionally high probability of acquiring the more common variant (Boyd \& Richerson, 1985; Deffner et al., 2021; Denton et al., 2020). Conformist transmission and its opposite, anti-conformist transmission, are chosen without considering the cost of success (Boyd \& Richerson, 2005). We assume that selforganized cycles occur during the periods of sociopolitical and economic stasis in populations' long-term development, while reflective cycles result from deep societal transformations. Overlap between the two types of cycles at different taxonomic orders should also not be excluded. Developing our understanding of repetitive patterns in cultural dynamics, this study specifically focuses on self-organized cycles.

As an alternative to the majority of other models of cultural evolution, the mathematical component of our approach simultaneously considers the behavior of cultural traits at different taxonomic orders and does not include innovation rate as one of the model input parameters. Therefore, the development of this alternative approach suggests the introduction of the toy model of cultural evolution. As already discussed in archaeological studies (and beyond), the label "toy model" does not denigrate the model's relevance. Instead, application of toy models aims to understand the relationship between the key parameters, evaluate the effect of these parameters on model behavior, and avoid turning models into "black boxes" (Drost \& Vander Linden, 2018). Following the logic of modeling in physics (Feynman, 1965), we develop the model to explain specific patterns and processes in the archaeological record and then test its utility to explain the results of other models. More specifically, the repetitive patterns in hierarchically organized data are addressed through the replacement of cultural traits. We then explore the utility of the toy model to explain a shift from conformist to anticonformist transmission, open and closed phases in cultural evolution, probabilities for horizontal transmission at different orders of taxonomical hierarchy during open phases, and the impact of various factors on assemblages' diversity. Finally, we discuss the uncertainty of explanation in archaeology. However, let us begin by analyzing uncertainty (informational entropy) as the methodological tool underlying the identification of cultural cycles.

\section{Entropy and Cultural Cycles}

Current understandings of prehistoric cultural cycles are strongly related to the concept of informational entropy as a quantitative approach to the analysis of the archaeological record. Entropy is a measure of the diversity and uncertainty of information, and the probability of introducing a new element to the system (Shannon $\&$ Weaver, 1963). While developed in information theory, the concept of entropy is widely applied in various natural and social sciences to analyze systems' internal 
diversity. Archaeological applications mainly consider Shannon's (1948) entropy, also known as Shannon's diversity index (Bevan et al., 2013; Bobrowsky \& Ball, 1989; Crema, 2015; Dickens Jr. \& Fraser, 1984; Drost \& Vander Linden, 2018; Fedorov-Davydov, 1987; Furholt, 2012; Gjesfjeld et al., 2020a, b; Gronenborn et al., 2014, 2017, 2018, 2020; Justeson, 1973; Kandler \& Crema, 2019; Neiman, 1995; Nolan, 2020; Premo \& Kuhn, 2010; Shott, 2010). According to this approach, "unification" is not opposed to "diversity"; instead, both categories are considered to gradually replace each other. Notions of "more unified" or "more diverse" assemblages are replaced by the values of Shannon's entropy $(H)$. The latter is estimated as follows:

$$
H=-K \sum_{i=1}^{N} p_{i} \log p_{i}
$$

where $p_{i}$ is the proportion of elements belonging to the $i$ th type $\left(\sum p_{i}=1\right)$, and $K$ is the normalizing coefficient (Shannon, 1948).

Archaeological literature often intuitively considers assemblage diversity by accounting for only the number of artifact types or stylistic variation. For example, an increase in the number of pottery types intuitively means an increase in pottery diversity. In terms of analytical approaches, in this case, diversity equals the category of "richness" or maximal entropy discussed below (Lyman, 2008; Shott, 2010).

Application of Shannon's entropy simultaneously considers qualitative and quantitative characteristics of the analyzed sets. Let us illustrate this statement using the following example. Assume an assemblage of artifacts is composed of three types, A, B, and C. Let artifacts of type A comprise 0.8 of this set, while artifacts of types $\mathrm{B}$ and $\mathrm{C}$ account for 0.1 each (Fig. 1a: 1). According to formula $1(K=1)$, the entropy of the assemblage is estimated at c. 0.28 (Fig. 1b: 1). Now let us add artifacts of type $\mathrm{D}$ to this assemblage, setting the distribution of types $\mathrm{C}$ and $\mathrm{D}$ at 0.05 each (Fig. 1a: 2). Then, the proportion of artifacts of type $\mathrm{A}$ is decreased to 0.6, while the proportion of type B and $\mathrm{C}$ artifacts is increased to 0.2 each (Fig. 1a: 3 ). Remarkably, the change in artifact proportions results in higher internal assemblage diversity than the change in its qualitative composition. The obtained values of $H$ are c. 0.41 (change in proportions, Fig. 1b: 3) and c. 0.32 , respectively (change in composition, Fig. 1b: 2).

The maximal entropy, also known as Hartley's entropy (Hartley, 1928), corresponds with the uniform distribution of cultural traits across all types. This is illustrated by the increase of entropy in our example to c. 0.48 , which corresponds with an equal proportion of cultural traits of the three types (Fig. 1a: 4 and 1b: 4). Hartley's entropy $\left(H_{\text {max }}\right)$ is expressed as follows:

$$
H_{\text {max }}=\log S
$$

where $S$ is the number of system states.

Both Shannon's entropy and Hartley's entropy can be used to analyze artifact types belonging to a single order of taxonomic hierarchy. However, as recently explored by Ray J. Rivers and his co-authors (Rivers, in preparation), hierarchically organized archaeological data requires the application of Rényi's entropy. 

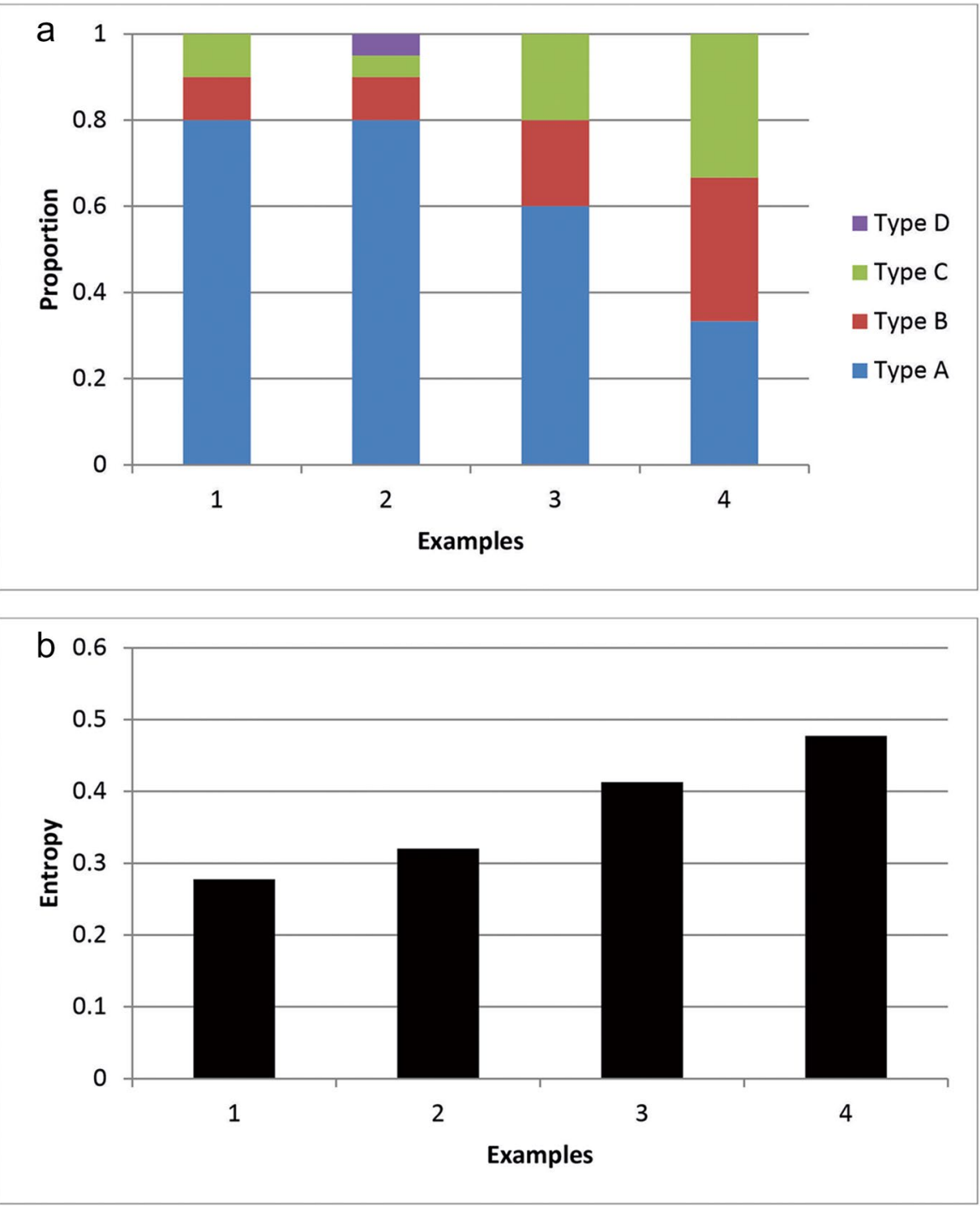

Fig. 1 Hypothetical example of the composition of an artifact set (a) and its diversity estimated as Shannon's entropy (b)

Rényi's entropy also generalizes Shannon's and Hartley's entropy, and is estimated as follows:

$$
H_{\lambda}=\frac{1}{1-\lambda} \log \left(\sum_{i=1}^{N} p_{i}^{\lambda}\right) ; \lambda \geq 0, \lambda \neq 1
$$

where $H_{\lambda}$ is Rényi's entropy of order $\lambda$ (Rényi, 1961). 
Formula 3, as the value of $H_{\lambda}$ approaches zero, has properties of Hartley's entropy (formula 2). If $\lambda$ in formula 3 approaches one, then formula 3 has properties of Shannon's entropy (formula 1).

One of the general properties of entropy is that it decreases with reduction (Gromov, 2013). In our case, reduction means a combination of lower order taxonomic units into higher order taxonomic units. Therefore, the number of units (system states) is reduced with the increasing order of taxonomic hierarchy, and Rényi's entropy increases as the order of a unit in archaeological taxonomy decreases. This statement can be illustrated by the following example: consider two artifact classes, with proportions of 0.6 and 0.4 . Each class includes two types distributed with proportions of 0.6 and 0.4 . Each of these types is divided into two subtypes, which also comprise 0.6 and 0.4 . The entropy of the subtypes (the lowest "archaeological order," $\lambda \rightarrow 0$ ) is estimated at c. 0.9 . The entropy of types (the second "archaeological order," $\lambda \rightarrow 1$ ) is estimated at c. 0.58 , while the entropy of class (the third "archaeological order," $\lambda=2$ ) is estimated at c. 0.28 (Fig. 2). Since Rényi's entropy decreases as the order of taxonomic hierarchy increases, human culture in its widest sense is associated with Min-entropy, $H_{m i n}$, which is expressed as:

$$
H_{\min }=-\log \max _{i} p_{i} \text {. }
$$

Let us consider artifact diversity at a single order of taxonomic hierarchy by considering the other hypothetical example. Diversity is estimated by applying Shannon's entropy to simplify explanations for cultural cycles observed in the archaeological record. According to the selected diversity measure (formula 1), more unified artifact sets are associated with the quantitative predominance of artifacts belonging to one or few types (Fig. 1: 1). Therefore, in the case of simple replacement of cultural traits by each other, cultural cycles of "unification-diversity-unification" are represented by the quantitative predominance of either one or several types shifted towards a more even distribution of different types, and then towards

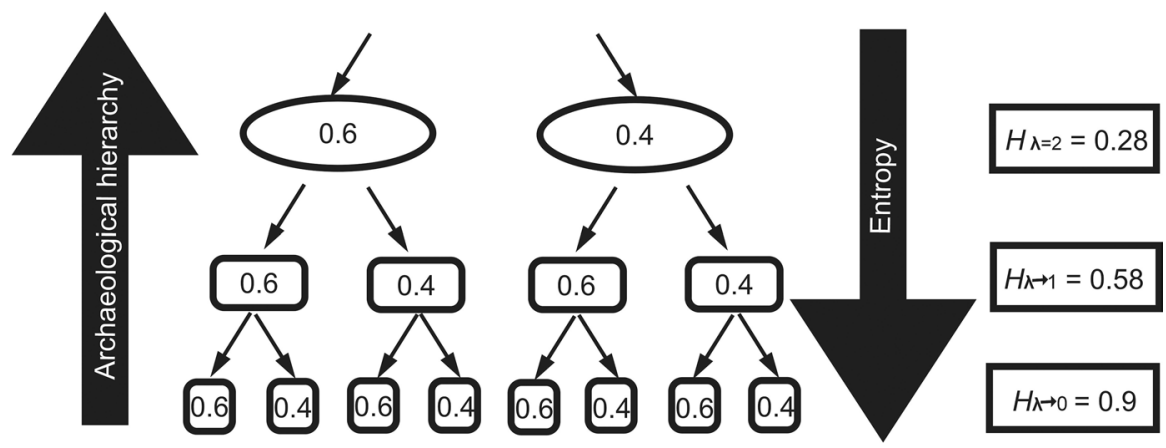

Fig. 2 Hypothetical example of the increase in Rényi's entropy corresponding to the decrease of the order in archaeological taxonomy. A total of 0.6 and 0.4 are the proportions of artifacts in taxonomic units and $H$ is the Rényi's entropy 
the predominance of other type(s). One may also consider a stable relative number of the most frequent type(s); this is contrasted with a sequential change among less frequent cultural traits. Both scenarios illustrate the vital role of types characterized by higher proportions (further labeled as primary types) in shaping the initial and final stages of cultural cycles. Therefore, self-organized cultural cycles are considered for the assessment of the frequency seriation, which is graphically represented as "battleship curves" (Lyman \& O'Brien, 2006; O’Brien \& Lyman, 2000, 2002), in the framework of informational entropy. Let us now consider the model of dynamic behavior which results in "battleship curves."

\section{Self-Organized Cultural Dynamics: a Toy Model}

Having framed modeling cycles in the context of the "culture as information" approach (Aunger, 2009; Boyd \& Richerson, 1985; Cavalli-Sforza \& Feldman, 1981; Krakauer et al., 2020; Nolan, 2020), we should begin by introducing the parameter of "informational capacity." This is defined as the sum of the total number of cultural traits which can be maintained by the system at all taxonomic scales and cultural memory. Cultural memory may be defined as mostly incomplete information on cultural traits previously available in the system, but not currently maintained. Informational capacity is further framed by interaction and communication, which are greatly impacted by both population size and density (Bentley et al., 2011; Chabai et al., 2020; Deffner et al., 2021; Fletcher, 1995; Henrich, 2004; Knappett, 2011; Lyman et al., 2000; Powell et al., 2010; Shennan, 2018; Sterelny, 2021).

Social knowledge is stored in collective mind. Individual human beings can remember c. 1.5 billion bytes of information (Landauer, 1986). However, expanding or reducing informational capacity does not simply mean adding or subtracting a person to or from a group. The clue to the change in informational capacity is the degree of social complexity reflected in the extent of similarity and difference between information shared by individuals in a group (Bentley et al., 2011). Therefore, the values of informational capacity may increase or decrease over time as a result of economic or sociopolitical transformations, which impact their interactioncommunication networks. In this case, system behavior leads to reflection cycles (e.g., Gronenborn et al., 2020; Hilbert, 2015; Kohler et al., 2009; Turchin, 2003). Since self-organized cultural cycles are unassociated with societal transformations, they are characterized instead by their stable informational capacity which remains a constant value over a period of time.

Our toy model distinguishes between more frequent primary traits and less frequent "secondary" cultural traits at the same order of taxonomic hierarchy; while conditionally dubbed "secondary" traits for the convenience of presentation, they also include tertiary types. The model is based on the assumption that system behavior results from primary components at different taxonomic hierarchical orders. Therefore, the behavior of secondary components has a limited freedom, as they are framed by the behavior of primary components. Assuming a limited number of cultural traits whose behavior defines a culture in its narrow sense (e.g., archaeological culture: Roberts \& Vander Linden, 2011), the model 
describes the subsequent replacement of these cultural traits by each other over time. In the case of conformist (biased) transmission, the extremely rapid spread of new "fashions" may be considered in the field of memetics, which originates from R. Dawkins' (1976/2016) Selfish Gene, first published in 1976. The intensive spread and "mutation" of cultural traits and their replacement by subsequent cultural traits over time lie at the core of archaeological thought and, probably, specifically distinguish cultural and biological evolution (e.g., Aunger, 2009; Laland et al., 2001; Shennan, 2002).

Since behavior of primary types is assumed to be independent and is approximated using the frequency seriation (see above), primary types' quantitative dynamics may be approached by applying the discrete version of the logistic equation. Widely known from chaos theory, the discrete version of the logistic equation describes different processes, such as turbulence and population dynamics (Feigenbaum, 1978, 1979; May, 1976). A number of studies applied this equation to archaeological data as well (Barceló \& Del Castillo, 2016; also see Kohler et al., 2009; Turchin \& Korotaev, 2006). The discrete version of the logistic equation is expressed as follows:

$$
M_{t+1}=M_{t} x\left(1-M_{t}\right)
$$

where $M_{t}$ and $M_{t+1}$ are the proportions of a component $M$ in a system at the time periods $t$ and $t+1$ respectively, and $x$ is the growth rate of component $M(x \leq 4)$.

The iterations of formula 5 lead to the transition from simple periodic behavior to a regime with complex aperiodic growth with period-doublings. System behavior is caused by the values of the growth rate $x$. If $x$ exceeds 1 but it is less than 2 , then $M_{t+1}$ stabilizes near the following value:

$$
M_{t+1}=\frac{x-1}{x}
$$

If $x$ belongs to the range between 2 and 3, the values of $M_{t+1}$ oscillate around the same value (formula 6), and then stabilize near this value. If $x$ is greater than 3 but is less than $3.45, M_{t+1}$ oscillates between two values; if $x$ exceeds 3.45 but is less than 3.54, $M_{t+1}$ oscillates between four values etc. (Feigenbaum, 1978, 1979; May, 1976).

We have made two modifications to the logistic equation. The first modification introduces thresholds to the proportions in formula 5. The second considers the decline in the proportion of cultural traits belonging to a primary type.

Thresholds are applied to consider the heterogonous character of archaeological data (and, therefore, culture in its wide sense) and its taxonomic structure (the number of cultural traits belonging to lower hierarchical orders is limited by the number of traits at higher orders' related units). Given that a primary trait $\alpha$ belongs to the set of an order $\lambda$ composed of $m$ primary traits and the related number of secondary traits, all taxonomically related to $m$ primary traits of an order $\lambda+1$, the threshold $C_{\alpha_{m \lambda+1}}$ is introduced into the logistic equation as its first modification: 


$$
\begin{gathered}
p_{\alpha_{m \lambda t+1}}=p_{\alpha_{m \lambda t}} \frac{r_{\alpha_{m \lambda}}}{C_{\alpha_{m \lambda+1}}}\left(C_{\alpha_{m \lambda+1}}-p_{\alpha_{m \lambda t}}\right) ; \\
p_{\alpha_{m \lambda t}} \leq C_{\alpha_{m \lambda+1}} \leq 1 ; \frac{r_{\alpha_{\lambda}}}{C_{\alpha_{m \lambda+1}}} \leq \frac{C_{\alpha_{m \lambda+1}}}{\left(C_{\alpha_{m \lambda+1}} / 2\right)^{2}}
\end{gathered}
$$

where $p_{\alpha_{m \lambda t}}$ and $p_{\alpha_{m \lambda_{t+1}}}$ are the proportions of cultural traits of the primary type $\alpha$ of an order $\lambda$ at time $t$ and $t+1$ respectively, and $r_{\alpha m_{\lambda}}$ is the replication rate of cultural traits of the primary type $\alpha$.

Formula 7 preserves the properties of formula 6 discussed above.

According to the second modification to the logistic equation, after the proportion of primary type starts to decrease, the secondary types become primary, while the primary type shifts to a secondary type. This decrease in proportion of traits may be slow or rapid. Slow decreases are associated with the relatively low values of $r_{\alpha m_{\lambda}} / C_{\alpha_{m \lambda+1}}$. Rapid declines are associated with relatively high values of $r_{\alpha m_{\lambda}} / C_{\alpha_{m \lambda+1}}$.

Let us now consider the behavior of secondary types framed by the changes in primary type proportions. For the sake of explanation, we will begin with a hypothetical data set composed of two types of artifacts. These are primary type $\alpha$ and secondary type $\beta$. Both types have a common threshold $C_{\alpha_{m \lambda+1}}$ equal to 1 . Since the proportion of artifacts of type $\beta$ depends on the change of proportion of artifacts of type $\alpha$ and replication rate of type $\beta$,

$$
\left\{\begin{array}{c}
p_{\beta_{t+1}}=1-p_{\alpha_{t+1}} \\
p_{\beta_{t+1}}=p_{\beta_{t} r_{\beta}}\left(1-p_{\beta_{t}}\right)
\end{array}\right.
$$

where $p_{\beta_{t}}$ and $p_{\beta_{t+1}}$ are the proportion of cultural traits of secondary type $\beta$ at the time $t$ and $t+1$ respectively, and $r_{\beta}$ is the replication rate of secondary type $\beta$.

Basing on formulas 7 and 8 , the total change in the proportions of artifacts referred to the primary type $\alpha$ and secondary type $\beta$ may be expressed as follows:

$$
p_{\alpha_{t}}\left(r_{\alpha}+r_{\beta}\right)\left(1-p_{\alpha_{t}}\right)=1
$$

Therefore, secondary type $\beta$ artifact replication rate is estimated as:

$$
\begin{gathered}
r_{\beta}=\frac{1}{p_{\alpha_{t}}\left(1-p_{\alpha_{t}}\right)}-r_{\alpha} \\
r_{\alpha} \leq 4 ; r_{\beta} \leq 4
\end{gathered}
$$

In order to consider the replication rates of multiple secondary types at different orders of taxonomic hierarchy, formula 10 may be generalized as follows:

$$
\sum r_{n m_{\lambda}} \frac{p_{n_{m \lambda t}}\left(C_{\alpha_{m \lambda+1}}-p_{n_{m \lambda t}}\right)}{p_{\alpha_{m \lambda t}}\left(C_{\alpha_{m \lambda+1}}-p_{\alpha_{m \lambda t}}\right)}=\frac{C_{\alpha_{m \lambda+1}}}{p_{\alpha_{m \lambda t}}\left(1-p_{\alpha_{m \lambda t}}\right)}-r_{\alpha}
$$

where $r_{n m_{\lambda}}$ is the replication rate of $n$th secondary type cultural traits and $p_{n_{m \lambda}}$ is the proportion of $n$th secondary type cultural traits having a common threshold $C_{\alpha_{m \lambda+1}}$ with primary type $p_{\alpha_{m \lambda} t}$. 
Considering multiple primary types at different taxonomic orders, the overall change in the proportions of cultural traits belonging to the secondary and primary types may be presented as:

$$
\begin{gathered}
\sum\left(p_{\alpha_{m \lambda t}} \frac{r_{\alpha m_{\lambda}}}{C_{\alpha_{m \lambda+1}}}\left(C_{\alpha_{m \lambda+1}}-p_{\alpha_{m \lambda t}}\right)\right)+\sum\left(p_{n_{m_{\lambda t}}} \frac{r_{n m_{\lambda}}}{C_{\alpha_{m \lambda+1}}}\left(C_{\alpha_{m \lambda+1}}-p_{n_{m \lambda t}}\right)\right)=1 \\
\sum C_{\alpha_{m \lambda+1}}=1
\end{gathered}
$$

Let us now return to the properties of the ratio $r_{\alpha m_{\lambda}} / C_{\alpha_{m \lambda+1}}$. At this ratio's increasing high values, the proportion of cultural traits belonging to primary type $\alpha$ rapidly increases and then significantly drops. At the given limits of $r_{\alpha m}$ and $r_{n m}$, (formulas 7 and 10), the respective increase in the proportion of cultural traits belonging to secondary types may be lower than the decrease of traits belonging to primary types. Therefore, there are cases when formula 12 is not satisfied.

Fig. 3 exemplifies the identified singularity in the model equations, i.e., system behavior reaching a point when the model equations break down. Assume a change in the proportion of artifacts belonging to two types, $\alpha$ and $\beta$. The primary type replication rate equals 3.645. The secondary type replication rate is estimated according to formula 10. The proportion of primary type $\alpha$ artifacts increases from 0.6 in the first unit of time to 0.875 in the second unit of time, while the proportion of artifacts belonging to secondary type $\beta$ decreases from 0.4 to 0.125 . In the third unit of time, the proportion of artifacts belonging to type $\alpha$ drops to 0.399 . However, under the highest possible value of $r_{\beta}$ given by formula 10 , artifacts belonging to type $\beta$ can reach only 0.439 . Therefore, the sum of the proportion of artifacts of both types is equal to 0.838 (Fig. 3).

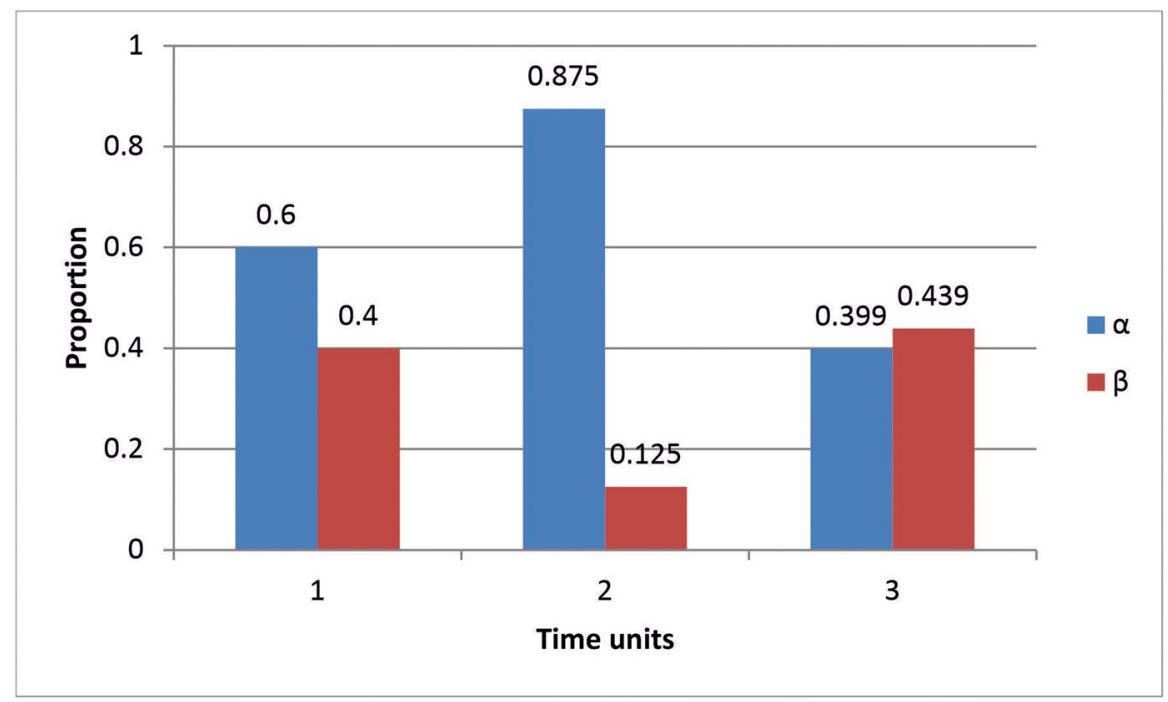

Fig. 3 Hypothetical example representing the singularity in equation 12 (the replication rate in primary type is equal to 3.645 ) 
This singularity may be interpreted as the open phase of the system, when innovations are introduced to the existing set of cultural traits. This interpretation is similar to the understanding of a singularity in artificial intelligence and technology, as an unpredictable societal transformation subsequently replacing a rapid increase in technology (Shanahan, 2005; also see Bentley et al., 2011). The key point in this similarity is the rapid growth preceding significant system's reorganization. At first glance, such an approximation for the rapid decline in cultural trait proportion might seem an oversimplification. However, this may be an example of cultural mutation or a form of selection bias. To illustrate this, consider an individual's music playlist. They may choose to play some tracks increasingly often for a given period of time, before the frequency with which a particular track is played suddenly drops. While the track is still listened to, it is played less frequently, while other songs increasingly take its place, and additional new tracks are added to the playlist. Examples of the rapid increase followed by significant drops may be also found in names, buzzwords, scientific terms etc. (Bentley et al., 2011).

Modeling the selection process and the introduction of innovations requires developing new equations or modifying previously existing approaches for further integration into our toy model. We currently suggest the following correction to the model equations, which allows us to avoid the identified singularity by adding the parameter describing the introduction of innovations to a set. Following our assumption on open phases in the system behavior, the sum of the proportions of innovative traits introduced into a set $\left(\sum p_{\gamma_{\lambda_{t+1}}}\right)$ is framed by the proportions of cultural traits belonging to the primary and secondary types in the set in the preceding time unit:

$$
\begin{aligned}
& \sum p_{\gamma_{\lambda_{t+1}}}=1-\left(\sum\left(p_{\alpha_{m \lambda t}} \frac{r_{\alpha_{m \lambda}}}{C_{\alpha_{m \lambda+1}}}\left(C_{\alpha_{m \lambda+1}}-p_{\alpha_{m \lambda t}}\right)\right)+\sum\left(p_{n_{m_{\lambda t}}} \frac{r_{n_{m_{\lambda}}}}{C_{\alpha_{m \lambda+1}}}\left(C_{\alpha_{m \lambda+1}}-p_{n_{m \lambda t}}\right)\right)\right) \\
& 0 \leq p_{\gamma_{\lambda}} \leq 1
\end{aligned}
$$

While the ratio $r_{\alpha_{m_{\lambda}}} / C_{\alpha_{m_{\lambda+1}}}$ does not reach substantively high values to move a set to a singularity in the subsequent time unit, the $\sum p_{\gamma_{t_{t+1}}}$ equals zero. When this ratio reaches substantively high values, a set is moved to a singularity in a subsequent time unit. During the time unit associated with the singularity, the proportion of primary trait available in the set drops, and the values of $\sum p_{\gamma_{\lambda_{t+1}}}$ exceed zero.

Integrating diversity at different scales, the dynamics of cultural traits replacing each other and the introduction of innovations are represented by:

$$
H_{\lambda_{i+1}}=\frac{1}{1-\lambda} \log \left(\sum\left(p_{a_{m \lambda \lambda}} \frac{r_{\alpha m_{\lambda}}}{C_{\alpha_{m \lambda+1}}}\left(C_{\alpha_{m i+1}}-p_{\alpha_{m \lambda \lambda}}\right)\right)^{\lambda}+\sum\left(p_{n_{m_{\lambda}+}} \frac{r_{n m_{\lambda}}}{C_{\alpha_{m \lambda+1}}}\left(C_{\alpha_{m_{\lambda+1}}}-p_{n_{m \lambda \lambda}}\right)\right)^{\lambda}+\sum p_{\gamma_{\lambda_{\lambda+1}}}{ }^{\lambda}\right)
$$

Formula 14 describes cultural dynamics at the two nearest orders of taxonomic hierarchy, which result in repetitive patterns sequentially processing the stages of unification, diversity, and return to unification of archaeological assemblages. Iterating this equation at the other taxonomic orders, the one obtains assemblage diversity composed of hierarchically organized cultural traits, which are 
Fig. 4 Model behavior illustrated by the hypothetical example of the cultural set. The hypothetical artifact set is divided into two types, each composed of two variants. Artifact types replace each other over time (a). The resulting behavior in variants leads to the introduction of innovation, "Variant B3" (b). The resulted values of Rényi's entropy indicate different intensiveness of cultural dynamics at different orders of taxonomic hierarchy (c)

selectively neutral or passed through the conformist transmission. Let us illustrate the model behavior and its outcomes.

\section{Results}

One more hypothetical set of cultural traits exemplifies the behavior of our toy model (Fig. 4). Consider a class of artifacts composed of two types, "A" and "B," distributed with proportions 0.7 and 0.3. Each type is composed of two variants. These are the variants "A1" (70\% of type "A"), "A2" (30\% of type "A"), "B1" (70\% of type "B"), and "B2" (30\% of type "B"). The threshold of variants $\left(C_{\alpha_{m \lambda+1}}\right)$ equals the proportions of types they compose at each unit of time. The values of $p_{n_{m_{\lambda t}}}$ are estimated according to formula 12 . The replication rate $r_{\alpha_{m_{\lambda}}}$ of primary variants is identical to the replication of the related types.

The replication rate of primary type "A" and variant "A1" is initially set for 2.5. Primary type "A" decreases with this replication rate and becomes a secondary type. Respectively, secondary type " $B$ " increases with the replication rate of c. 2.26 and becomes primary. Type " $\mathrm{B}$ " further grows supported by the replication rate, adding 0.2 for each time unit. The model represents a gradual replacement of type "A" by type "B" (Fig. 4a). The corresponding variants' behavior is characterized by fluctuations in variants of type "B" (Fig. 4b).

Variant "A1" decreases during time unit 2, subsequently increases during time units 3 to 7, and decreases again during time units 8 and 9. Variant "A2" rapidly increases in time unit 2 , then decreases in time units $3-7$, and increases again in time units 8 and 9. Variant "B1" oscillates in frequency during time units 1-5. The decline in variant "B2" in time unit 5 , when formula 12 reaches a singularity, causes the introduction of innovating variant "B3" (formula 14). After its introduction, the replication rate in one of the secondary variants, $r_{n_{m_{\lambda}}}$, is set to an arbitrary taken value of 8 in time units 5-9. Notably, despite setting the replication rate of variant "B3" to a constant value, its proportion neither remains constant nor gradually increases or decreases over time as one would expect. Instead, the proportion of variant "B3" increases in time unit 7 and decreases in time units 8 and 9, in the result of changing the proportions of type "B," i.e., the related unit of the higher order of hierarchy. Variants "B1" and "B2" fluctuate in relatively narrow ranges during time units 7-9 (Fig. 4b).

Different behavior at different taxonomic hierarchal orders results in different values of entropy $H_{\lambda}$ (Fig. 4c). This makes four important conclusions possible. First, as suggested by the properties of Rényi's entropy incorporated into the model, the diversity increases from the top down in archaeological taxonomies. 

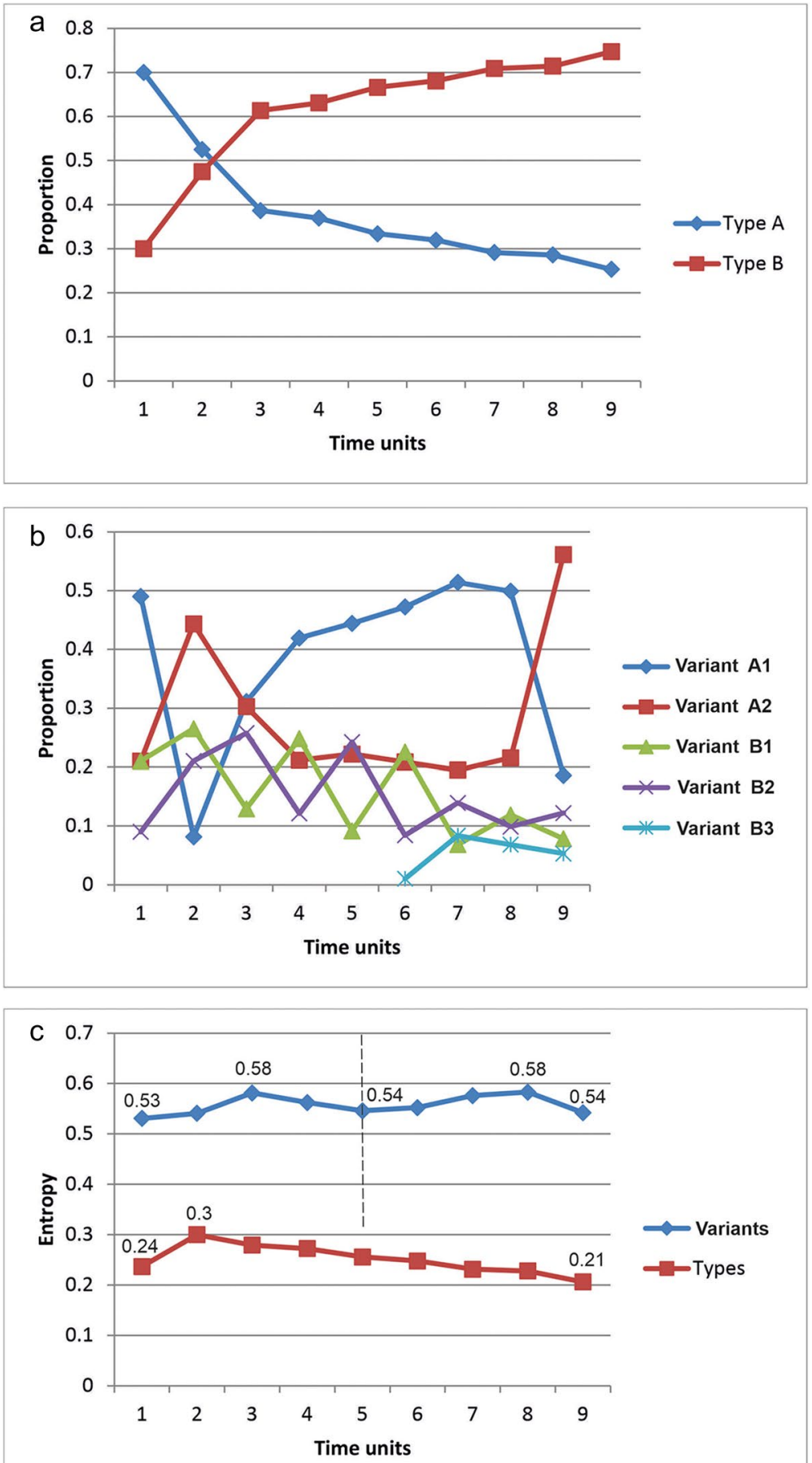
Second, changes in the cultural trait proportions result in cyclical trends, which represent the transition of an assemblage from unification to diversity and then back to unification (increase and subsequent decrease in entropy are represented in Fig. 4c: types increase in time unit 1-2; variants increase in time units 1-3 and 5-8). More unified assemblages exhibit the quantitative predominance of one or a few cultural traits. More diverse sets are characterized by a more even distribution of traits belonging to the same taxonomic order. Therefore, the highest values of entropy in our hypothetical example (Fig. 4c, types-time unit 2, variants-time units 3, 7, and 8) correspond to the lowest difference in trait frequency (Fig. 4a: time unit 2, and 4b: time unit 3), also accounting an increase in the proportion of innovative trait occurring in the system (Fig. 4b: time units 7 and 8).

Third, the intensity of cultural dynamics increases from the top down in archaeological hierarchies. Type behavior in our example is shaped into a single cycle representing the increase and subsequent gradual decrease in diversity. Two smaller cycles represent the behavior of variants (Fig. 4c: time units 1-5 and 5-9).

Fourth, as demonstrated by the behavior of "Type B" and "Variant B3" which replication rate was set to a constant value, the proportion of the lower order's taxonomic unit is framed by the proportion of the higher order's taxonomic unit (Fig. 4b). Therefore, these results are indicative for interrelated behavior at different taxonomic orders.

Let us now turn to the utility of our approach to generalize the outcomes of other models dealing with patterns and processes in cultural evolution.

\section{Discussion and Conclusion}

The presented model describes the dynamics of cultural systems incorporating hierarchically organized traits, which results in self-organized cultural cycles. These patterns do not correspond to bias in assemblages following economic or sociopolitical changes. The increase and rapid decline in primary types and their subsequent replacement are controlled by the ratio $r_{\alpha m_{\lambda}} / C_{\alpha_{m \lambda+1}}$, or the ratio between the replication rate of cultural traits and the proportion of traits of the related unit of the higher taxonomic order. The relationship between cultural traits' behavior at different taxonomic orders is controlled by the parameter $C_{\alpha_{m \lambda+1}}$.

The replication rate of a cultural trait is also a key parameter in a number of neutral models of cultural evolution. For example, F. Neiman's (1995) model produces similar behavior depending on two factors: the rate of innovation and the random process of cultural drift. E. Gjesfjeld and his co-authors' model (2020a) considers cultural development in the context of replication rates and the extension of traits. The factor of cultural transmission may be added to these two factors (Gjesfjeld et al., 2020b).

The replication rate represents a change in the proportion of a cultural trait over time. Its values may be affected by demography, the analyzed phenomena's duration, and artifacts' use life. In this way, the proposed approach generalizes the outcomes of other models. 
A trait's replication rate may be increased or decreased depending on the growth or decline of the number of "consumers" and "producers." This agrees with the outcomes of our model and approaches which link cultural diversity to population size (Bentley et al., 2011; Creanza et al., 2017; Crema \& Lake, 2015; Henrich, 2004; Lycett \& Norton, 2010; Neiman, 1995; Richerson et al., 2009). The increase in population size and density is considered as one of the factors which influence the different spread rates between modern and prehistoric cultural traits (e.g., Bauman, 2001; Baumeister, 2005). Of course, when dealing with cultural evolution, we should consider the effective population size instead of the total population number, as was first suggested in the analysis of genetic analogies decades ago (Wright, 1931). In genetics, effective population size is a measure of the random genetic drift on a population genetic feature of interest in a real population (Premo, 2016). In respect to culturally evolving traits, the complex relationship between census population size and effective population size comprises innovation flow, different modes of cultural transmission, and social network structure (Deffner et al., 2021; Premo, 2015, 2016, 2021; Premo \& Scholnick, 2011).

Other factors which impact replication rates, and which therefore influence increases or decreases in cultural diversity, are the duration of occupations or analyzed periods, and different artifact type life use (Mesoudi \& O'Brien, 2008; Perreault, 2019; Premo, 2014; Schiffer, 1987; Shott, 1989, 2010; Surovell, 2009). For instance, variability in Paleolithic and Mesolithic arrowheads is generally higher than the diversity of scrapers (Tomasso \& Rots, 2021), because the use life of an arrowhead is much shorter than the use life of a scraper. Of course, both guided and non-guided variations in these categories also impact their internal diversities (Deffner \& Kandler, 2019; Shennan, 2009). However, the major difference in these diversities may be explained exclusively by different replication rates. The proposed toy model produces cyclical cultural dynamics even when population size, artifact life use, and duration of the analyzed data are set as constant.

The model equations were initially focused on replacing cultural traits and the cycling nature of culture. However, the model also describes several empirically known patterns of cultural evolution: first, the cumulative nature of culture; and second, its punctuated, dynamic development, as reflected in the "open" and "closed" phases associated with different types of cultural transmission. The other important model outcomes are the appearance of innovations as large complex packages and the mechanics of cultural memory.

According to formula 11, the decrease in cultural traits among secondary types does not necessarily reach zero. For example, their number may take the values of $10^{-5}$ or lower orders, and as such is too small to be associated with absolute numbers greater than one. We tend to interpret such significantly small values as a representation of cultural memory (see above). This way the model "preserves" types (or the "ideas of a style") in a cultural system, even if they are not produced for a period of time. Even when they have passed out of use, these styles are preserved in cultural memory, and may be used again with the increase of values of the related $r_{n m_{\lambda}} / C_{\alpha_{m \lambda+1}}$. Such borrowing of "new" styles from the past is well-known from experiments and empirical evidence (Mesoudi, 2010; Premo \& Scholnick, 2011). 
Singularity in the model equations, which is associated with a significant decline in cultural traits among primary types, is interpreted as a state of openness to innovations. As an alternative to other models which assume a continuous innovation rate (Crema \& Lake, 2015; Henrich, 2004; Neiman, 1995; also see: Kandler $\&$ Crema, 2019), our approach suggests a discrete character of new cultural trait acceptance. This corresponds with the empirical observations and outcomes of other models, which consider the appearance of innovations as large complex packages (e.g., O’Brien \& Shennan, 2010; Shennan, 2002).

Let us consider how discrete character of innovation occurrence is derived from the model. According to formula 14, closed phases result in sufficiently high values of primary cultural traits' replication rate. Given a constant probability for copying errors, the number of copying errors increases proportionally to the increase in replication rate. The increasing number of copying errors increases the number of inventions as "creation of new ideas and objects." Therefore, a rapid increase in replication rate simultaneously moves an assemblage to the transition from closed to open phase with respect to the occurrence of innovations and increases the number of inventions which may be adopted (i.e., may become innovations) during open phase. Innovation is "an adoption of an idea or object by other agents" (definitions for the "invention" and "innovation" are derived from O'Brien and Bentley, 2021).

As shown by Eerkens and Lipo (2005), the increasing number of copying errors increases the variability of continuous cultural traits. By reassessing the variability of continuous traits as the increase in the number of discrete taxonomic units in a hierarchically considered trait, we find an agreement between their model and outcomes of our approach related to neutral evolution. In this way (taking into account the role of cultural memory), cultural systems incorporate an option for introducing not only external traits as innovations, but also internally developed inventions. The latter statement may be illustrated by the previously mentioned example in the Western Tripolye culture pottery assemblages, where sphero-conical vessels were replaced by biconical vessels (Diachenko et al., 2020; Ryzhov, 1993, 2000).

With respect to the biased cultural transmission, closed phases in cultural dynamics are associated with conformist transmission, which is replaced by anti-conformist transmission and the adoption of innovations during open phases (formulas 13 and 14). Anti-conformist transmission, or negative frequency-dependent bias, describes the deliberate exclusion of previously "fashionable" traits in the copying process (Boyd \& Richerson, 1985, 2005; Deffner et al., 2020; Kohler et al., 2004; Shennan \& Wilkison, 2001).

It is also likely that the probabilities for innovation resulted from horizontal cultural transmission during open phases vary at different scales of taxonomic hierarchy (formula 14). Vertical transmission occurs between generations in the same population, while horizontal transmission describes the innovation flow between different populations (Boyd \& Richerson, 1985; Shennan, 2002).

For the sake of explanation, let us assume the following. First, the probability for borrowing an idea from "neighbor" assemblages is proportional to the number of units at the related taxonomic order in "neighbor" sets. Second, the probability for borrowing an idea from available inventions in a set is proportional to the number of inventions in this set. Third, there is an equal probability for adopting an available 
invention and a trait from a neighboring group's assemblage. The increase in the number of system states from the top to down in archaeological taxonomy generally decreases the values of $C_{\alpha_{m \lambda+1}}$ and, therefore, increases the values of the ratio $r_{\alpha m_{\lambda}} / C_{\alpha_{m_{\lambda+1}}}$ even with decreasing values of $r_{\alpha m_{\lambda}}$ top-down the taxonomic hierarchy (formula 14). Therefore, open phases occur more frequently in lower orders of archaeological taxonomy (as exemplified by the model results: Fig. 4c). The number of copying errors decreases with the decrease in replication rate top-down the hierarchy during closed phases. This decrease in inventions reduces the probabilities for "offering" an idea during an open phase with a decreasing taxonomic order. Therefore, the probability for horizontal transmission increases top-down in archaeological taxonomy.

The increase in the values of $C_{\alpha_{m \lambda+1}}$ with a growing order of taxonomic hierarchy during closed phases also requires an increase in the replication rate $r_{\alpha m_{\lambda}}$ in order to achieve the values of $r_{\alpha m_{\lambda}} / C_{\alpha_{m \lambda+1}}$ which support the stable or growing numbers of primary cultural traits. The increase in $r_{\alpha m_{\lambda}}$ causes an increase in copying errors, which in turn increases the number of inventions, and thus the number of possible innovations further occurring in open phase. Therefore, the probabilities for horizontal transmission decrease with the increase of unit's taxonomic order. For example, consider pottery decoration from a taxonomic perspective. Some "elements" of ornamentation ("lowest" taxonomic order) are horizontally transmitted more frequently than their combinations ("medium" order), while ornamentation "motives" (comprising combinations of "elements") are relatively rare. For instance, numerous examples for this statement are presented in the volume "Import and Imitation in Archaeology" (Biehl \& Rassamakin, 2008), labeling cultural traits passed through horizontal transmission as "imitations" and "influences." Generally, this conclusion also agrees with the ethnographic observations of Shennan and Steele (1999). The selection process and constraints of introducing complex traits into different cultural systems should be considered with further development of the model. Also, these model outcomes limit the explanatory potential of memetics to the lower orders of archaeological taxonomies resulting in the values of the $r_{\alpha m_{\lambda}} / C_{\alpha_{m \lambda+1}}$ ratio, which are sufficiently high to support rapid spread, replacement, and mutation of memes.

From the perspective of the model outcomes related to cultural hierarchy and heterogeneity, different concepts of cultural evolution are not considered here as contradictory. The qualitative and quantitative dynamics of cultural traits of low orders of taxonomic hierarchy and artifacts characterized by a short-term use life are better explained by gradual evolution. The evolution of artifacts characterized by medium- and long-term use life and cultural traits belonging to higher orders of taxonomic hierarchy fits the concept of punctuated evolution. The latter assumes long periods of relative stasis, interrupted by periods of rapid bursts of innovation (Bak, 1996; Bentley, 2003; Dow \& Reed, 2011; Gould \& Eldredge, 2003; Lyman \& O'Brien, 1998). Closed and open phases of cultural evolution, as presented in the toy model, are respectively associated with periods of stasis and bursts of change. It is important to note that the concept of punctuated equilibrium is often misunderstood. One of the key issues is the misinterpretation of species branching resulting from the stratigraphic position of fossils in sediments, which are different in age, but have parallel layers (for the extended discussion see O'Brien \& Lyman, 2000). The 
crucial agreement between punctuated equilibrium and the outcomes of our model is the increasing relative stasis (duration of closed phases) with an increasing taxonomic order.

Basing the presented model on entropy as a measure of the diversity and uncertainty of information, it would be reasonable to conclude with uncertainty of archaeological thought. To a great extent, this uncertainty is caused by the quality of archaeological record (Perreault, 2019). However, singularities in the current version of model equations may lead to a somewhat disappointing conclusion regarding our limited ability to predict cultural evolution at its widest chronological ranges, at least with respect to unbiased and conformist cultural transmission. If Shanahan's (2005) understanding of singularity as unpredictable transformation also applies to our model, then precise predictions are only possible between singularities. Such predictions of the assemblages' composition during a shift from conformist to anti-conformist transmission will remain unreached. Since our model preserves the chaotic properties of the logistic equation, it is sensitively dependent on the initial conditions, and long-term evolution will remain a space for surprises and uncertainties. On one hand, this possibility somehow reflects the current state of the art-otherwise archaeologists' and anthropologists' recent work on detailed models would apply to materials from the evolution of Paleolithic geometric ornaments on mammoth bones to Impressionism. On the other hand, the ability to predict the occurrence of singularities from the values of model parameters is already a big advantage.

Besides indicating possible limitations in approaching cultural evolution, comparing our model with the other models exemplifies two significant issues in modeling components of archaeological explanation. These issues are the different cultural and social processes behind similar data distributions and different input parameters causing similar model behavior.

Self-organized and reflective cultural cycles represent, respectively, social stability and social change. However, despite the different cultural development mechanics, both types of cycles may be represented by similar artifact distribution patterns (cf. Kandler \& Crema, 2019; O’Dwyer \& Kandler, 2017). This similarity emphasizes that the relationship between societal transformations and cultural development is far more complex than generally assumed. A significant number of models and empirical observations indicate the reflection of adaptation to fluctuating environment or sociopolitical and economic development in material culture change, including the correspondence between cultural and social cycles (Deffner \& Kandler, 2019; Gronenborn et al., 2020; Kohler et al., 2020; Roux, 2010, 2014; Roux et al., 2017). A number of our model outcomes show that similar patterns in prehistoric assemblage distributions may strictly result from unbiased or conformist transmission. This finds an agreement with the conclusions of Kandler and Crema (2019), which emphasize the underlying need to carefully interpret the consistency between data and neutral models, because other transmission models may be equally consistent. Hence, the identification of a cultural cycle does not necessarily mean the identification of social transformations or social stasis.

Our approach finds an agreement with the results of other models in the possibility of slowing or accelerating cultural dynamics by changes in population size, the 
life use of artifacts, and/or the duration of the analyzed data. In other words, explanation in particular studies of some artifact categories can be uncertain because of the possibility of simultaneous effect of these factors on data distribution, regardless of whether inductive or deductive approaches are applied to data analysis. As we have shown in the "Entropy and Cultural Cycles" section which assessed "battleship curves" in frames of informational entropy, one obtains cycles in unification-diversity-unification of assemblages' diversity. However, "battleship curves" result from either the neutral models including innovation rate as an input parameter (Kandler \& Crema, 2019; Neiman, 1995), or, as in our approach in relation to neutral evolution, without including this parameter.

How can future research find a path forward to overcome these issues? The answer lies in contextualizing analyzed materials in a wider framework based on their taxonomic hierarchical scale, and the simultaneous behavior of other categories of interdisciplinary data. At first glance, this answer sounds somewhat exaggerated. However, it is grounded in the important property of entropy, that is, that the entropy (uncertainty) of non-interacting systems generally exceeds the entropy of interacting systems (Gromov, 2013). Therefore, data contextualization as a consideration of different interacting categories at different scales reduces a myriad of multiple possible explanations to a much shorter list. Extending this conclusion to modeling in archaeology, we consider it reasonable to test the utility of models with the aim of describing specific patterns and processes to explain other patterns and processes.

Further development of the presented toy model should consider the spatial distribution of cultural traits. More specifically, the model should be integrated with approaches to analyze cultural incubators (Crema \& Lake, 2015), cultural distances (Nakoinz, 2014), isolation-by-distance principle (Shennan et al., 2015), and other related models.

Acknowledgements We are sincerely grateful to Ray J. Rivers for discussing his ideas on cultural dynamics and approaches to its understanding with us, commenting on the draft of this paper, and for permission to cite his ongoing, but not yet published research. We are infinitely grateful to Michael J. O'Brien, who chose to not remain anonymous, and two anonymous reviewers for their valuable critical comments and suggestions helping to improve this paper. Many thanks are addressed to Erika Ruhl for editing the English language and her valuable comments on the draft of this manuscript.

Funding This paper was made possible by a grant from the Science Centre of Poland, awarded to Iwona Sobkowiak-Tabaka (2018/29/B/HS3/01201). Open access to this article was made possible by the program "Excellence Initiative - Research University" financed by Adam Mickiewicz University in Poznań (decision no. 011/08/POB5/0053).

Availability of Data and Materials Not applicable

Code Availability Not applicable

\section{Declarations}

Ethics Approval The authors are responsible for correctness of the statements provided in the manuscript.

Consent to Participate Not applicable 
Consent for Publication Both authors gave explicit consent to submit an article.

Conflict of Interest The authors declare no competing interests.

Open Access This article is licensed under a Creative Commons Attribution 4.0 International License, which permits use, sharing, adaptation, distribution and reproduction in any medium or format, as long as you give appropriate credit to the original author(s) and the source, provide a link to the Creative Commons licence, and indicate if changes were made. The images or other third party material in this article are included in the article's Creative Commons licence, unless indicated otherwise in a credit line to the material. If material is not included in the article's Creative Commons licence and your intended use is not permitted by statutory regulation or exceeds the permitted use, you will need to obtain permission directly from the copyright holder. To view a copy of this licence, visit http://creativecommons.org/licen ses/by/4.0/.

\section{References}

Aunger, R. (2009). Human communication as niche construction. In S. J. Shennan (Ed.), Pattern and process in cultural evolution (pp. 33-43). University of California Press.

Bak, P. (1996). How nature works? The science of self-organized criticality. Copernicus.

Barceló, J., \& Del Castillo, F. (2016). Simulating the past for understanding the present. A critical review. In J. Barceló \& F. Del Castillo (Eds.), Simulating prehistoric and ancient worlds. Computational social sciences (pp. 1-140). Springer. https://doi.org/10.1007/978-3-319-31481-5_1

Bauman, Z. (2001). Globalizacja. I co z tego dla ludzi wynika. Państwowy Instytut Wydawniczy.

Baumeister, R. F. (2005). The cultural animal. Human, nature, meaning and social life. Oxford University Press.

Bentley, R. A. (2003). An introduction to complex systems. In R. A. Bentley \& H. D. G. Maschner (Eds.), Complex systems and archaeology. Empirical and theoretical foundations (pp. 9-23). The University of Utah Press.

Bentley, A., Earles, M., \& O’Brien, M. J. (2011). I'll have what she's having: Mapping social behavior. The MIT Press.

Bentley, R. A., \& Maschner, H. D. G. (2004). Complex systems and archaeology. Empirical and theoretical foundations. The University of Utah Press.

Bentley, R. A., \& Maschner, H. D. G. (2009). Complexity theory. In R. A. Bentley, H. D. G. Maschner, \& C. Chippindale (Eds.), Handbook of archaeological theories (pp. 245-270). Altamira Press.

Bevan, A., Crema, E., Li, X., \& Palmisano, A. (2013). Intensities, interactions and uncertainties: Some new approaches to archaeological distributions. In A. Bevan \& M. Lake (Eds.), Computational approaches to archaeological space (pp. 27-52). Left Coast Press.

Biehl, P. F., \& Rassamakin, Y. Y. (Eds.). (2008). Import and imitation in archaeology. Beier \& Beran.

Bobrowsky, P. T., \& Ball, B. F. (1989). The theory and mechanics of ecological diversity in archaeology. In R. D. Leonard \& G. T. Jones (Eds.), Quantifying diversity in archaeology (pp. 4-12). Cambridge University Press.

Boyd, R., \& Richerson, P. J. (1985). Culture and the evolutionary process. The University of Chicago Press.

Boyd, R., \& Richerson, P. J. (2005). The origin and evolution of cultures. Oxford University Press.

Cavalli-Sforza, L. L., \& Feldman, M. (1981). Cultural transmission: A quantitative approach. Princeton University Press.

Chabai, V. P., Stupak, D. V., Veselskiy, A. P., \& Dudnyk, D. V. (2020). The cultural and chronological variability of the Epigravettian of the Middle Dnieper basin. Arkheolohiya, 2, 5-31. https://doi.org/ 10.15407/archaeologyua2020.02.005

Creanza, N., Kolodny, O., \& Feldman, M. W. (2017). Cultural evolutionary theory: How culture evolves and why it matters. PNAS, 114(30), 7782-7789. https://doi.org/10.1073/pnas.1620732114

Crema, E. R. (2015). Time and probabilistic reasoning in settlement analysis. In J. A. Barcelo \& I. Bogdanovic (Eds.), Mathematics in archaeology (pp. 314-334). CRC Press. 
Crema, E. R., \& Lake, M. W. (2015). Cultural incubators and spread of innovations. Human Biology, 87(3), 151-168. https://doi.org/10.13110/humanbiology.87.3.0151

Dawkins, R. (1976/2016). The Selfish Gene (40 th anniversary edition). Oxford University Press.

Deffner, D., \& Kandler, A. (2019). Trait specialization, innovation, and the evolution of culture in fluctuating environments. Palgrave Communications, 5, 147. https://doi.org/10.1057/s41599-019-0360-4

Deffner, D., Kandler, A., \& Fogarty, L. (2021). Effective population size for culturally evolving traits. Retrieved September $14^{\text {th }}, 2021$, from bioRxiv preprint. https://doi.org/10.1101/2021.09.09.459561

Denton, K. K., Ram, Y., Liberman, U., \& Feldman, M. W. (2020). Cultural evolution of conformity and anticonformity. PNAS, 117(24), 13603-13614. https://doi.org/10.1073/pnas.2004102117

Diachenko, A., Sobkowiak-Tabaka, I., \& Ryzhov, S. (2020). Approaching the unification and diversity of pottery assemblages: The case of Western Tripolye culture ceramics in the Southern Bug and Dnieper Interfluve, 4100 - 3600 cal BC. Documenta Praehistorica, 47, 522-535. https://doi.org/ $10.4312 /$ dp. 47.30

Dickens Jr., R. S., \& Fraser, M. D. (1984). An information-theoretic approach to the analysis of cultural interactions in the Middle Woodland period. Southeastern Archaeology, 3(2), 144-152.

Dow, G. K., \& Reed, C. G. (2011). Stagnation and innovation before agriculture. Journal of Economic Behavior and Organization, 77(3), 339-350. https://doi.org/10.1016/j.jebo.2010.11.006

Drost, C., \& Vander Linden, M. (2018). Toy story: Homophily, transmission and the use of simple simulation models for assessing variability in the archaeological record. Journal of Archaeological Method and Theory, 25(4), 1087-1108. https://doi.org/10.1007/s10816-018-9394-y

Eerkens, J. W., \& Lipo, C. P. (2005). Cultural transmission, copying errors, and the generation of variation in material culture and the archaeological record. Journal of Anthropological Archaeology, 24(4), 316-334. https://doi.org/10.1016/j.jaa.2005.08.001

Fedorov-Davydov, G. A. (1987). Statistical methods in archaeology. Vysshaya Shkola [English translation of the Russian title].

Feigenbaum, M. J. (1978). Quantitative universality for a class of nonlinear transformations. Journal of Statistical Physics, 19(1), 25-52. https://doi.org/10.1007/BF01020332

Feigenbaum, M. J. (1979). The universal metric properties of nonlinear transformations. Journal of Statistical Physics, 21(6), 669-706. https://doi.org/10.1007/BF01107909

Feynman, R. P. (1965). The character of physical law. Penguin Books.

Fletcher, R. (1995). The limits of settlement growth. A theoretical outline. Cambridge University Press.

Furholt, M. (2012). Kundruci: Development of social space in a Late Neolithic tell-settlement in Central Bosnia. In R. Hofmann, F.-K. Moetz, \& J. Müller (Eds.), Tells: social and environmental space (pp. 203-220). Rudolf Habelt GmbH.

Furholt, M. (2021). Mobility and social change: Understanding the European Neolithic period after the archaeogenetic revolution. Journal of Archaeological Research, 29, 481-535. https://doi.org/10. 1007/s10814-020-09153-x

Gjesfjeld, E., Silvestro, D., Chang, J., Koch, B., Foster, J. G., \& Alfaro, M. E. (2020a). A quantitative workflow for modeling diversification in material culture. PLoS One, 15(2), e0227579. https://doi. org/10.1371/journal.pone.0227579

Gjesfjeld, E., Crema E. R., \& A. Kandler (2020b). Analysing the diversification of cultural variants using longitudinal richness data. Retrieved November 24th, 2020, from OSFPreprints. DOI: https://doi. org/10.31219/osf.io/nkfet

Gould, S. J., \& Eldredge, N. (2003). Punctuated equilibrium comes of age. Nature, 366(6452), $223-227$.

Gromov, M. (2013). In a search for a structure, part 1: On entropy. Retrieved September $17^{\text {th }}, 2019$, from https://www.ihes.fr/ gromov/wp-content/uploads/2018/08/structre-serch-entropy-july5-2012.pdf

Gronenborn, D., Strien, H.-C., Dietrich, S., \& Sirocko, F. (2014). 'Adaptive cycles' and climate fluctuations: A case study from Linear Pottery culture in western Central Europe. Journal of Archaeological Science, 51, 73-83. https://doi.org/10.1016/j.jas.2013.03.015

Gronenborn, D., Strien, H.-C., \& Lemmen, C. (2017). Population dynamics, social resilience strategies, and adaptive cycles in early farming societies of SW Central Europe. Quaternary International, 446, 54-65. https://doi.org/10.1016/j.quaint.2017.01.018

Gronenborn, D., Strien, H.-C., van Dick, R., \& Turchin, P. (2018). Social diversity, social identity, and the emergence of surplus in western central European Neolithic. In H. Meller, D. Gronenborn, \& R. Risch (Eds.), Surplus without the state - Political forms in prehistory. 10th Archaeological Conference of Central Germany, October 19 - 21, 2017 in Haale (Saale) (pp. 201-220). Grafisches Centrum Cuno $\mathrm{GmbH}$ and Co. 
Gronenborn, D., Strien, H.-C., Wirtz, K., Turchin, P., Zeilhofer, C., \& van Dick, R. (2020). Inherent collapse? Social dynamics and external forcing in Early Neolithic and modern Southwestern Germany. In F. Riede \& P. Sheets (Eds.), Going forward by looking back: Archaeological perspectives on socio-ecological crisis, response, and collapse (pp. 333-366). Berghahn.

Hartley, R. V. L. (1928). Transmission of information. Bell System Technical Journal, VII(3), 535-563. https://doi.org/10.1002/j.1538-7305.1928.tb01236.x

Henrich, J. (2004). Demography and cultural evolution: How adaptive cultural processes can produce maladaptive losses - the Tasmanian case. American Antiquity, 69(2), 197-214. https://doi.org/10. $2307 / 4128416$

Hilbert, M. (2015). A review of large-scale 'How much information?' inventories: Variations, achievements and challenges. Information Research, 20(4), 688 Online publication. www.infor mationr.net/ir/20-4/paper668.html

Justeson, J. S. (1973). Limitations of archaeological inference: An information theoretic approach with applications in methodology. American Antiquity, 38(2), 131-149. https://doi.org/10.2307/ 279360

Kandler, A., \& Crema, E. R. (2019). Analysing cultural frequency data: Neutral theory and beyond. In A. Prentiss (Ed.), Handbook of evolutionary research in archaeology (pp. 83-108). Springer. https://doi.org/10.1007/978-3-030-11117-5_5

Knappett, C. (2011). An archaeology of interaction. Network perspectives on material culture and society. Oxford University Press.

Kohler, T. A., Cole, S., \& Ciupe, S. (2009). Population and warfare: A test of the Turchin model in Pueblo Societies. In S. J. Shennan (Ed.), Pattern and process in cultural evolution (pp. 304332). University of California Press.

Kohler, T. A., Ellyson, L. J., \& Bocinsky, R. K. (2020). Beyond one-shot hypothesis: Explaining three increasingly large collapses in the Northern Pueblo Southwest. In F. Riede \& P. Sheets (Eds.), Going forward by looking back: Archaeological perspectives on socio-ecological crisis, response, and collapse (pp. 333-366). Berghahn.

Kohler, T. A., VanBuskirk, S., \& Ruscavage-Barz, S. (2004). Vessels and villages: Evidence for conformist transmission in early village aggregations on the Pajarito Plateau, New Mexico. Journal of Anthropological Archaeology, 23(1), 100-118. https://doi.org/10.1016/j.jaa.2003.12.003

Krakauer, D., Bertschinger, N., Olbrich, E., Flack, J. C., \& Ay, N. (2020). The information theory of individuality. Theory in Biosciences, 139, 209-223. https://doi.org/10.1007/ s12064-020-00313-7

Kristiansen, K. (2014). Towards a new paradigm? The third science revolution and its possible consequences in archaeology. Current Swedish Archaeology, 22, 11-34.

Laland, K. N., Odling-Smee, J., \& Feldman, M. W. (2001). Cultural niche construction and human evolution. Journal of Evolutionary Biology, 14, 22-33.

Landauer, T. K. (1986). How much do people remember? Some estimates of the quantity of learned information in the long-term memory. Cognitive Science, 10, 477-493.

Lycett, S. J., \& Norton, C. J. (2010). A demographic model for Paleolithic technological evolution: The case of East Asia and the Movius line. Quaternary International, 211(1), 55-65. https://doi.org/10. 1016/j.quaint.2008.12.001

Lyman, R. L. (2008). Quantitative Paleozoology. Cambridge University Press.

Lyman, R. L., \& O’Brien, M. J. (1998). The goals of evolutionary archaeology: History and explanation. Current Anthropology, 39(5), 615-652. https://doi.org/10.1086/204786

Lyman, R. L., \& O’Brien, M. J. (2003). W.C. McKern and the Midwestern taxonomic method. The University of Alabama Press.

Lyman, R. L., \& O'Brien, M. J. (2006). Measuring time with artifacts. A history of methods in American archaeology. University of Nebraska Press.

Lyman, P., Varian, H. R., Dunn, J., Strygin, A., \& Swearingen, K. (2000). How much information 2000. University of California Retrieved March 22, 2021, from http://www.webcitation.org/6bZr3vVr3

May, R. L. (1976). Simple mathematical models with very complicated dynamics. Nature, 261, 459-467. https://doi.org/10.1038/261459a0

Mesoudi, A. (2010). The experimental study of cultural innovations. In M. J. O’Brien \& S. J. Shennan (Eds.), Innovation in cultural systems: Contributions from evolutionary anthropology (pp. 175191). The MIT Press.

Mesoudi, A. (2011). Cultural evolution. How Darwinian theory can explain human culture and synthesize the social science. The University of Chicago Press. 
Mesoudi, A., \& O'Brien, M. J. (2008). The cultural transmission of Great Basin projectile-point technology. I. An experimental simulation. American Antiquity, 73(1), 3-28. https://doi.org/10.1017/ S0002731600041263

Mosionzhnik, L. A. (2006). A man in the face of culture ((2nd). ed.). Vysshaya Antropologicheskaya Shkola [English translation of the Russian title].

Nakoinz, O. (2014). Fingerprinting Iron Age communities in South-West Germany and an integrative theory of culture. In C. N. Popa \& S. Stoddart (Eds.), Fingerprinting the Iron Age: Approaches to identity in Iron Age. Integrating South-Eastern Europe into the debate (pp. 87-199). Oxbow Books.

Neiman, F. D. (1995). Stylistic variation in the evolutionary perspective: Inferences from decorative diversity and interassemblage distance in Illinois Woodland ceramic assemblage. American Antiquity, 60(1), 7-36. https://doi.org/10.2307/282074

Nolan, K. C. (2020). Bringing archaeology into the information age: Entropy, noise, channel capacity, and information potential in archaeological significance assessments. Quality and Quantity, 54, 1171-1196. https://doi.org/10.1007/s11135-020-00980-0

O'Brien, M. J., \& Bentley, R. A. (2021). Genes, culture, and the human niche: An overview. Evolutionary Anthropology: Issues, News, and Reviews, 30, 40-49. https://doi.org/10.1002/evan.21865

O’Brien, M. J., \& Lyman, R. L. (2000). Applying evolutionary archaeology. Plenum.

O'Brien, M. J., \& Lyman, R. L. (2002). Seriation, stratigraphy and index fossils. The backbone of archaeological dating. Kluwer Academic Publishers.

O'Brien, M. J., \& Shennan, S. J. (2010). Innovation in cultural systems: Contributions from evolutionary anthropology. The MIT Press.

O’Dwyer, J. P., \& Kandler, A. (2017). Inferring processes of cultural transmission: The critical role of rare variants in distinguishing neutrality from novelty biases. Philosophical Transactions of the Royal Society B, 372, 20160426. https://doi.org/10.1098/rstb.2016.0426

Perreault, C. (2019). The quality of the archaeological record. The University of Chicago Press.

Powell, A., Shennan, S. J., \& Thomas, M. G. (2010). Demography and variation in the accumulation of culturally inherited skills. In M. J. O'Brien \& S. J. Shennan (Eds.), Innovation in cultural systems: Contributions from evolutionary anthropology (pp. 137-160). The MIT Press.

Premo, L. S. (2014). Cultural transmission and diversity in time-averaged assemblages. Current Anthropology, 55(1), 105-114.

Premo, L. S. (2015). Mobility and cultural diversity in central-place foragers: Implications for the emergence of modern human behavior. In A. Mesoudi \& K. Aoki (Eds.), Learning strategies and cultural evolution during the Palaeolithic (pp. 45-65). Springer.

Premo, L. S. (2016). Effective population size and the effect of demography on cultural diversity and technological complexity. American Antiquity, 81(4), 605-622. https://doi.org/10.1017/S0002 73160010099X

Premo, L. S. (2021). Population size limits the coefficient of variation in continuous traits affected by proportional copying error (and why this matters for studying cultural transmission). Journal of Archaeological Method and Theory, 28(2), 512-534. https://doi.org/10.1007/s10816-020-09464-9

Premo, L. S., \& Kuhn, S. L. (2010). Modelling effects of local extinctions on culture change and diversity in the Paleolithic. PLoS One, 5(12), e15582.

Premo, L. S., \& Scholnick, J. B. (2011). The spatial scale of social learning affects cultural diversity. American Antiquity, 76(1), 163-176.

Rényi, A. (1961). On measures of entropy and information. In J. Neyman (Ed.), Proceedings of the Fourth Berkeley Symposium on Mathematical Statistics and Probability (Vol. 1, pp. 547-561). University of California Press.

Richerson, P. J., Boyd, R., \& Bettinger, R. L. (2009). Cultural innovations and demographic change. Human Biology, 81(3), 211-235. https://doi.org/10.3378/027.081.0306

Roberts, B. W., \& Vander Linden, M. (Eds.). (2011). Investigating archaeological cultures: Material culture, variability, and transmission. Springer.

Roux, V. (2010). Technological innovations and developmental trajectories: Social factors as evolutionary forces. In M. J. O’Brien \& S. J. Shennan (Eds.), Innovation in cultural systems: Contributions from evolutionary anthropology (pp. 217-233). The MIT Press.

Roux, V. (2014). Spreading of innovative technical traits and cumulative technical evolution: Continuity or discontinuity? Journal of Archaeological Method and Theory, 20, 312-330. https://doi.org/10. 1007/s10816-012-9153-4 
Roux, V., Bril, B., Cauliez, J., Goujon, A.-L., Lara, C., Manen, C., de Saulieu, G., \& Zangato, E. (2017). Persisting technological boundaries: Social interactions, cognitive correlations and polarization. Journal of Anthropological Archaeology, 48, 320-335. https://doi.org/10.1016/j.jaa.2017.09.004

Ryzhov, S. (1993). Nebelevskaya group of the Tripolye culture. Archaeology, 3, 101-114 [English translation of the Ukrainian title].

Ryzhov, S. (2000). Painted ceramics of the Tomashovskaya local group of Tripolye culture. Stratum Plus, 2, 459-473 [English translation of the Russian title].

Schiffer, M. B. (1987). Formation processes of the archaeological record. Academic Press.

Shanahan, M. (2005). The technological singularity. The MIT Press.

Shannon, C. (1948). A mathematical theory of communication. Bell System Technical Journal, 27(3), 379-423. https://doi.org/10.1002/j.1538-7305.1948.tb01338.x

Shannon, C., \& Weaver, W. (1963). The mathematical theory of communication. University of Illinois Press.

Shennan, S. (2002). Genes, memes and human history. Darwinian archaeology and cultural evolution. Thames \& Hudson.

Shennan, S. J. (2008). Evolution in archaeology. Annual Review of Anthropology, 37, 75-91. https://doi. org/10.1146/annurev.anthro.37.081407.085153

Shennan, S. J. (ed.). (2009). Pattern and process in cultural evolution. An introduction. In S. J. Shennan (Ed.), Pattern and process in cultural evolution (pp. 1-18), University of California Press.

Shennan, S. J. (2018). The first farmers of Europe. An evolutionary perspective. Cambridge University Press.

Shennan, S. J., Crema, E. R., \& Kerig, T. (2015). Isolation-by-distance, homophily, and "core" vs. "package" cultural models in Neolithic Europe. Evolution and Human Behavior, 36(2), 103-109. https:// doi.org/10.1016/j.evolhumbehav.2014.09.006

Shennan, S. J., \& Steele, J. (1999). Cultural learning in hominids: A case study from Neolithic Europe. In H. O. Box \& K. R. Gibson (Eds.), Mammalian social learning: Comparative and ecological perspectives (pp. 367-388). Cambridge University Press.

Shennan, S. J., \& Wilkison, J. R. (2001). Ceramic style change and neutral evolution: A case study from Neolithic Europe. American Antiquity, 66(4), 577-593. https://doi.org/10.2307/2694174

Shott, M. J. (1989). On tool-class use lives and the formation of archaeological assemblages. American Antiquity, 54(1), 9-30. https://doi.org/10.2307/281329

Shott, M. J. (2010). Size dependence in assemblage measures: Essentialism, materialism, and "SHE" analysis in archaeology. American Antiquity, 75(4), 886-906. https://doi.org/10.7183/0002-7316. 75.4 .886

Sterelny, K. (2021). Demography and cultural complexity. Synthese, 198, 8557-8580. https://doi.org/10. 1007/s11229-020-02587-2

Surovell, T. A. (2009). Toward a behavioral ecology of lithic technology: Cases from Paleoindian archaeology. University of Arizona Press.

Tomasso, A., \& Rots, V. (2021). Looking into Upper Paleolithic gear: The potential of an integrated techno-economic approach. Journal of Anthropological Archaeology, 61, 101240. https://doi.org/ 10.1016/j.jaa.2020.101240

Turchin, P. (2003). Historical dynamics. Why states rise and fall. Princeton University Press.

Turchin, P., \& Korotaev, A. (2006). Population dynamics and internal warfare: A reconsideration. Social Evolution and History, 5(2), 112-147.

Turchin, P., \& Nefedov, S. A. (2009). Secular cycles. Princeton University Press.

Wright, S. (1931). Evolution in Mendelian populations. Genetics, 16, 97-159.

Publisher's Note Springer Nature remains neutral with regard to jurisdictional claims in published maps and institutional affiliations. 